\title{
Utility of Intraoperative Parathormone Assay as an Index to Successful Parathyroidectomy
}

\author{
Ranjeetha Shenoy, Arun Behl, and Tushar Pawar \\ Fortis Hospitals, Mulund, Mumbai 400080, India \\ Correspondence should be addressed to Ranjeetha Shenoy; rshenoysurgeon@gmail.com
}

Received 15 December 2013; Revised 5 May 2014; Accepted 7 May 2014; Published 19 May 2014

Academic Editor: Tullio Florio

Copyright (C) 2014 Ranjeetha Shenoy et al. This is an open access article distributed under the Creative Commons Attribution License, which permits unrestricted use, distribution, and reproduction in any medium, provided the original work is properly cited.

Introduction. Surgery is the definitive treatment for primary hyperparathyroidism (PHP). Focused approaches for excision of single gland pathology are gaining popularity. Preoperative parathyroid localization and intraoperative parathormone (IOPTH) assay are essential components of successful parathyroidectomy using focused approach. Objective. To evaluate the efficacy of IOPTH in patients undergoing surgery for PHP. Methods. Retrospective review of twelve patients who underwent surgery for PHP at tertiary corporate hospital in Mumbai, India, between January 2009 and December 2012. Results. IOPTH had true results in 10 patients $(83 \%)$ and led to unnecessary further exploration in 1 patient $(8 \%)$. The concordance rate between ultrasonogram, sestamibi, and IOPTH was $66 \%$. The mean decay of IOPTH was $65 \%$, and all patients were normocalcemic at the end of six months. Conclusion. IOPTH is a useful adjunct to predict successful removal of the involved gland.

\section{Introduction}

Primary hyperparathyroidism (PHP) is due to excessive parathormone secreted by one or more parathyroid glands and leads to varied manifestations due to hypercalcemia. Parathyroid adenoma is the most common cause of primary hyperparathyroidism and as much as $85 \%$ are single adenomas [1]. Surgery is the definitive therapy for PHP, which includes removal of affected parathyroid gland(s) [2]. Success rates for surgical treatment depend on the skill and experience of the surgeon in finding and recognizing the pathologic changes and excising the correct amount of hyperfunctioning parathyroid tissue [3]. Cure rate has been reported to be in the range of $94-100 \%$ for bilateral neck, as well as a less invasive surgery, more than 6 months after parathyroidectomy [4-13]. Bilateral neck exploration (BNE) has been traditionally performed where routine identification of all enlarged (involved) and normal parathyroid is mandatory and only enlarged gland(s) is/are excised. Of late, focused approaches for excision of single gland pathology are gaining popularity.
Preoperative parathyroid localization imaging study and IOPTH are essential components of focused approach. Various techniques are described and the open procedure seems to be the most common and either uses a standard collar incision with unilateral dissection only or uses a minimal incision just over the location of the abnormal parathyroid gland. Imperfect preoperative localization, the intrinsic rate of bilateral multiglandular disease, and operative complications have been implicated as causes of a failed minimally invasive parathyroidectomy resulting in either conversion to an open bilateral procedure or a repeat operation. There is increased potential for recurrent laryngeal nerve injury because of the limited exposure involved in a minimally invasive parathyroidectomy [14].

IOPTH is a useful measure because in parathyroid surgery PTH is produced only in parathyroid glands and the intact 84-residue molecule has a half-life of about less than 5 minutes. Also secretion of PTH is suppressed in normal parathyroid glands after the removal of all hyperfunctioning tissue and therefore PTH concentrations should decline rapidly after all hypersecreting parathyroid tissue has been removed [15]. The current usual criteria for IOPTH 
measurement describe a decrease of $50 \%$ or over from the baseline (preincision), pointing out surgical cure and predicting normocalcemia. We have used two samples to evaluate the IOPTH decay: the preincision and 10 minutes postexcision of hyperfunctioning parathyroid. Significant fall in PTH was defined using Miami criterion, that is, $50 \%$ fall from baseline at 10 minutes after resection of the last abnormal gland.

\section{Subjects and Methods}

Retrospective evaluation of twelve patients who underwent surgery for PHP with a curative intent at our centre between January 2009 and December 2012 was performed. There were 9 females and 3 males. The mean age was $58.2 \pm$ 14.6 yrs (range 31 yrs to 84 yrs). Serum calcium was measured by $\mathrm{o}$-cresolphthalein complexone and serum albumin was measured by a colorimetric assay. Intact PTH was assayed by a sandwich electrochemiluminescence immunoassay. All the patients had hypercalcemia (defined as serum calcium $>$ $10.5 \mathrm{mg} / \mathrm{dL}$ ); adjusted serum calcium levels ranged between 10.9 and $14.4 \mathrm{mg} / \mathrm{dL}$ (mean: $11.98 \pm 1.0 \mathrm{mg} / \mathrm{dL}$ ). All patients had increased serum parathormone levels (normal reference range: $11-54 \mathrm{pg} / \mathrm{mL}$ ) ranging between $62.65 \mathrm{pg} / \mathrm{mL}$ and $1865 \mathrm{pg} / \mathrm{mL}$ (mean: $591.3 \pm 536.9 \mathrm{pg} / \mathrm{mL}$ ). All patients underwent ultrasonogram (USG) of neck, whereas sestamibi scan was not feasible in three patients due to technical reasons. On imaging, the maximum diameter of parathyroid gland ranged between 0.9 and $4.0 \mathrm{cms}$ (average: $2.3 \mathrm{cms}$ ). All the patients were operated electively. All the patients were operated by the same surgeon using a 3-centimetre skin crease incision. Unilateral exploration was done in ten patients and bilateral exploration was done in two patients, owing to presence of coexistent papillary carcinoma of thyroid. Intact PTH was measured in the operating room using the rapid assay before induction of anesthesia (preincision) and at $10 \mathrm{~min}$ after gland resection. A 50\% decline in PTH concentration from baseline was considered significant decay, suggesting successful excision of the hyperfunctional gland.

\section{Results}

Surgical excision led to significant decay of PTH (>50\%) in ten patients $(83 \%)$. The mean decay in these patients was $65 \%$. The concordance rate between preoperative ultrasonogram, sestamibi, and IOPTH was $66 \%$ in our study. Two patients $(17 \%)$ had decay of $<50 \%$. One patient who had sustained rise of PTH after excision of preoperatively localized gland underwent bilateral exploration. There was apparent enlargement of all glands and suspicious nodes. Excision of all four glands and frozen section confirmation, followed by autotransplant into forearm, were done. The nodes were sent frozen section examination, which had no evidence of malignancy; hence, no dissection was performed. The histopathology of this patient revealed solitary adenoma and no evidence of hyperplasia or malignancy. In another patient who had sustained rise of IOPTH post excision, neck exploration was done and it was found that rest of the glands were grossly normal and no further excision was done. In ten patients, histology confirmed the presence of discrete, encapsulated adenomas, containing sheets and islands of eosinophilic and chief cells, with no capsular invasion. There was no evidence of hyperplasia or carcinoma in any patient. One patient had oxyphil adenoma variant and another had lipoadenoma. In one patient, double adenoma was detected on neck ultrasonogram preoperatively, and, on excision of both adenomas, PTH fell to baseline levels. In the immediate postoperative period, three patients had hypocalcemia, who were managed with oral calcium and vitamin D supplementation. None of the patients had severe hypocalcemia requiring intravenous calcium. There was no other complication noted. During followup, all patients remained normocalcemic at 6 months postop. Also the serum PTH levels were below baseline $(<54 \mathrm{pg} / \mathrm{mL})$ except one patient who had persistent elevation of PTH levels but was asymptomatic and normocalcemic.

\section{Discussion}

Nussbaum et al. were the first to describe the use of a rapid assay for $\mathrm{PTH}$ in patients undergoing neck exploration for hyperparathyroidism [16]. Garner and Leight [17] found that the intraoperative PTH assay predicted postoperative outcome in $96 \%$ of 130 consecutive cases of primary hyperparathyroidism, whereas Gordon et al. [18] validated assay accuracy in 72 patients undergoing bilateral exploration for primary hyperparathyroidism, using gross morphologic criteria to identify uniglandular or multiglandular disease. There was no correlation between the magnitudes in IOPTH drop with parathyroid gland weight [19]. In addition, IOPTH level monitoring was found to be safe and effective for thoracoscopic mediastinal parathyroidectomy [20]. Lately a retrospective study involving seven patients who underwent MIP has been published from India, where IOPTH levels fell in six of the seven patients [21].

In addition, the rapid PTH assay has been shown to be useful in cases of secondary-tertiary hyperparathyroidism [22-24], as well as in reoperative cases for failed surgery or recurrent disease [25]. The assay has also been reported to predict severe postoperative hypocalcemia in reoperative patients with multiglandular disease [26]. There are several pitfalls with IOPTH assay. Intraoperative PTH monitoring does not accurately detect the presence of double adenomas [27] and does not significantly affect the overall success of traditional surgery with bilateral neck exploration [28]. Surgical failures [29] in IOPTH can be due to excessive preexcision manipulation, leading to a falsely elevated initial reading and false postexcision drop in levels, or rarely due to a dominant tumor suppressing other tumors in the multiple endocrine neoplasia (MEN) syndrome [30]. The assay is intended to provide guidance and should complement, not replace, the judgment and experience of the surgeon to determine surgical cure.

In our study of 12 patients, IOPTH had true results in 10 patients $(83 \%)$ and led to unnecessary further exploration in 1 patient $(8 \%)$ because of presumed additional hypersecreting 
gland(s). The mean decay of IOPTH in our study was $65 \%$, and all patients were normocalcemic at the end of six months. The routine use of IOPTH assay for PHP has led to focused approach surgery being performed, has obviated routine frozen section examination of the excised gland, and has contributed to successful treatment of PHP at our hospital.

\section{Conflict of Interests}

The authors declare that there is no conflict of interests regarding the publication of this paper.

\section{References}

[1] R. L. Rossi, S. G. ReMine, and E. P. Clerkin, "Hyperparathyroidism," Surgical Clinics of North America, vol. 65, no. 2, pp. 187-209, 1985.

[2] S. J. Silverberg, J. P. Bilezikian, H. G. Bone, G. B. Talpos, M. J. Horwitz, and A. F. Stewart, "Therapeutic controversy: therapeutic controversies in primary hyperparathyroidism," The Journal of Clinical Endocrinology and Metabolism, vol. 84, no. 7, pp. 2275-2285, 1999.

[3] G. L. Irvin III, V. D. Dembrow, and D. L. Prudhomme, "Operative monitoring of parathyroid gland hyperfunction," American Journal of Surgery, vol. 162, no. 4, pp. 299-302, 1991.

[4] B. Chiu, C. Sturgeon, and P. Angelos, "What is the link between nonlocalizing sestamibi scans, multigland disease, and persistent hypercalcemia? A study of 401 consecutive patients undergoing parathyroidectomy," Surgery, vol. 140, no. 3, pp. 418-422, 2006.

[5] D. Calva-Cerqueira, B. J. Smith, M. L. Hostetler et al., "Minimally invasive parathyroidectomy and preoperative MIBI scans: correlation of gland weight and preoperative PTH," Journal of the American College of Surgeons, vol. 205, no. 4, pp. S38-S44, 2007.

[6] J. Mark Jones, C. F. J. Russell, W. Rodney Ferguson, and J. D. Laird, "Pre-operative sestamibi-technetium subtraction scintigraphy in primary hyperparathyroidism: experience with 156 consecutive patients," Clinical Radiology, vol. 56, no. 7, pp. 556-559, 2001.

[7] R. M. Palmer and J. S. Lokey, "Is minimally invasive parathyroidectomy reasonable in the nonuniversity setting?" American Journal of Surgery, vol. 192, no. 6, pp. 865-868, 2006.

[8] A. Bergenfelz, P. Lindblom, S. Tibblin, and J. Westerdahl, "Unilateral versus bilateral neck exploration for primary hyperparathyroidism: a prospective randomized controlled trial," Annals of Surgery, vol. 236, no. 5, pp. 543-551, 2002.

[9] J. Westerdahl and A. Bergenfelz, "Sestamibi scan-directed parathyroid surgery: potentially high failure rate without measurement of intraoperative parathyroid hormone," World Journal of Surgery, vol. 28, no. 11, pp. 1132-1138, 2004.

[10] D. Moka, E. Voth, M. Dietlein, A. Larena-Avellaneda, and H. Schicha, "Technetium 99m-MIBI-SPECT: a highly sensitive diagnostic tool for localization of parathyroid adenomas," Surgery, vol. 128, no. 1, pp. 29-35, 2000.

[11] R. E. Goldstein, D. Billheimer, W. H. Martin et al., "Sestamibi scanning and minimally invasive radioguided parathyroidectomy without intraoperative parathyroid hormone measurement," Annals of Surgery, vol. 237, no. 5, pp. 722-731, 2003.
[12] R. Udelsman, "Six hundred fifty-six consecutive explorations for primary hyperparathyroidism," Annals of Surgery, vol. 235, no. 5, pp. 665-672, 2002.

[13] J. M. Ruda, C. S. Hollenbeak, and B. C. Stack Jr., "A systematic review of the diagnosis and treatment of primary hyperparathyroidism from 1995 to 2003," Otolaryngology-Head and Neck Surgery, vol. 132, no. 3, pp. 359-372, 2005.

[14] F. D. Moore Jr., F. Mannting, and M. Tanasijevic, "Intrinsic limitations to unilateral parathyroid exploration," Annals of Surgery, vol. 230, no. 3, pp. 382-391, 1999.

[15] A. R. Brasier, C.-A. Wang, and S. R. Nussbaum, "Recovery of parathyroid hormone secretion after parathyroid adenomectomy," The Journal of Clinical Endocrinology and Metabolism, vol. 66, no. 3, pp. 495-500, 1988.

[16] S. R. Nussbaum, A. R. Thompson, K. A. Hutcheson, R. D. Gaz, and C. A. Wang, "Intraoperative measurement of parathyroid hormone in the surgical management of hyperparathyroidism," Surgery, vol. 104, no. 6, pp. 1121-1127, 1988.

[17] S. C. Garner and G. S. Leight Jr., "Initial experience with intraoperative PTH determinations in the surgical management of 130 consecutive cases of primary hyperparathyroidism," Surgery, vol. 126, no. 6, pp. 1132-1138, 1999.

[18] L. L. Gordon, W. H. Snyder III, F. Wians Jr., F. Nwariaku, and L. T. Kim, "The validity of quick intraoperative parathyroid hormone assay: an evaluation in seventy-two patients based on gross morphologic criteria," Surgery, vol. 126, no. 6, pp. 1030$1035,1999$.

[19] D. M. Carneiro, C. C. Solorzano, M. C. Nader et al., "Comparison of intraoperative iPTH assay (QPTH) criteria in guiding parathyroidectomy: which criterion is the most accurate?" Surgery, vol. 134, no. 6, pp. 973-981, 2003.

[20] T. L. Weigel, J. Murphy, L. Kabbani, A. Ibele, and H. Chen, "Radioguided thoracoscopic mediastinal parathyroidectomy with intraoperative parathyroid hormone testing," Annals of Thoracic Surgery, vol. 80, no. 4, pp. 1262-1265, 2005.

[21] K. S. Padma, K. Lakshman, and S. S. Srikanta, "Feasibility of rapid parathormone assay for enabling minimally invasive parathyroid excision," Indian Journal of Surgery, vol. 75, no. 3, pp. 210-215, 2013.

[22] L. J. Sokoll, H. Drew, and R. Udelsman, "Intraoperative parathyroid hormone analysis: a study of 200 consecutive cases," Clinical Chemistry, vol. 46, no. 10, pp. 1662-1668, 2000.

[23] B. M. Clary, S. C. Garner, and G. S. Leight Jr., "Intraoperative parathyroid hormone monitoring during parathyroidectomy for secondary hyperparathyroidism," Surgery, vol. 122, pp. 10341039, 1997.

[24] F.-F. Chou, C.-H. Lee, J.-B. Chen, K.-T. Hsu, and S.-M. SheenChen, "Intraoperative parathyroid hormone measurement in patients with secondary hyperparathyroidism," Archives of Surgery, vol. 137, no. 3, pp. 341-344, 2002.

[25] G. L. Irvin III, A. S. Molinari, C. Figueroa, and D. M. Carneiro, "Improved success rate in reoperative parathyroidectomy with intraoperative PTH assay," Annals of Surgery, vol. 229, no. 6, pp. 874-879, 1999.

[26] D. M. Elaraj, A. T. Remaley, W. F. Simonds et al., "Utility of rapid intraoperative parathyroid hormone assay to predict severe postoperative hypocalcemia after reoperation for hyperparathyroidism," Surgery, vol. 132, no. 6, pp. 1028-1034, 2002.

[27] P. G. Gauger, G. Agarwal, B. G. England et al., "Intraoperative parathyroid hormone monitoring fails to detect double parathyroid adenomas: a 2-institution experience," Surgery, vol. 130, no. 6, pp. 1005-1010, 2001. 
[28] F. L. Starr, R. DeCresce, and R. A. Prinz, "Use of intraoperative parathyroid hormone measurement does not improve success of bilateral neck exploration for hyperparathyroidism," Archives of Surgery, vol. 136, no. 5, pp. 536-542, 2001.

[29] I. Emmolo, H. Dal Corso, G. Borretta et al., "Unexpected results using rapid intraoperative parathyroid hormone monitoring during parathyroidectomy for primary hyperparathyroidism," World Journal of Surgery, vol. 29, no. 6, pp. 785-788, 2005.

[30] S. Yavuz, W. F. Simonds, L. S. Weinstein et al., "Sleeping parathyroid tumor: rapid hyper function after removal of the dominant tumor," The Journal of Clinical Endocrinology and Metabolism, vol. 97, pp. 1834-1841, 2012. 


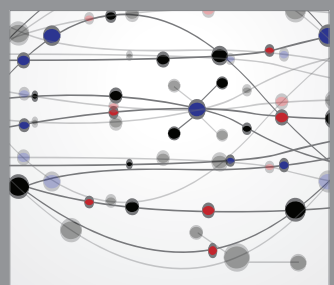

The Scientific World Journal
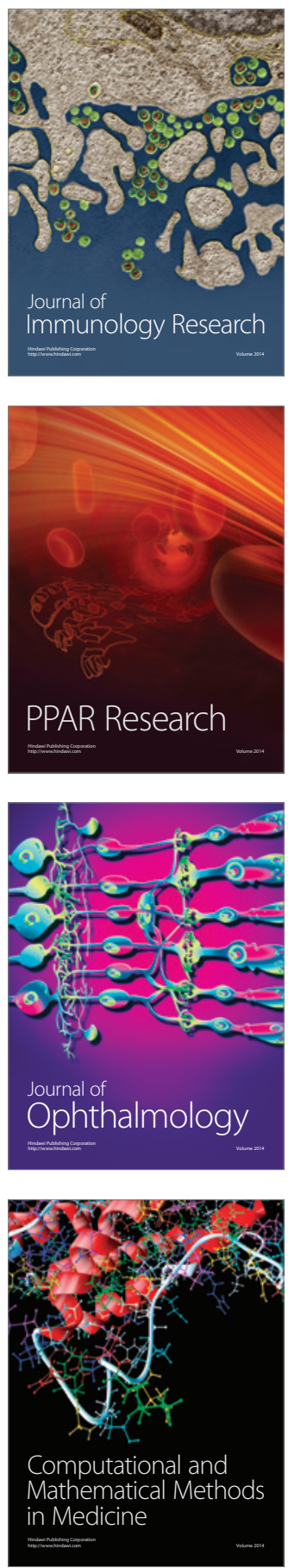

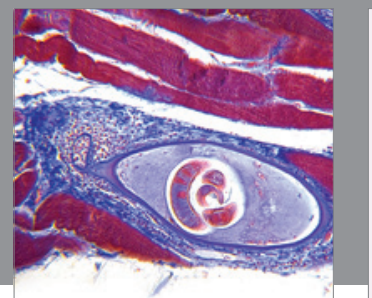

Gastroenterology

Research and Practice
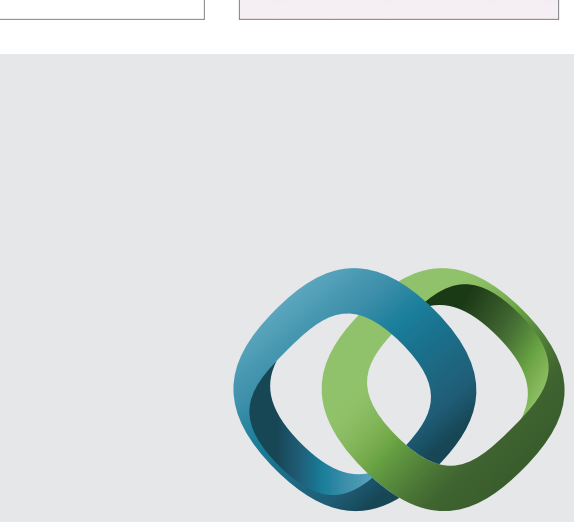

\section{Hindawi}

Submit your manuscripts at

http://www.hindawi.com
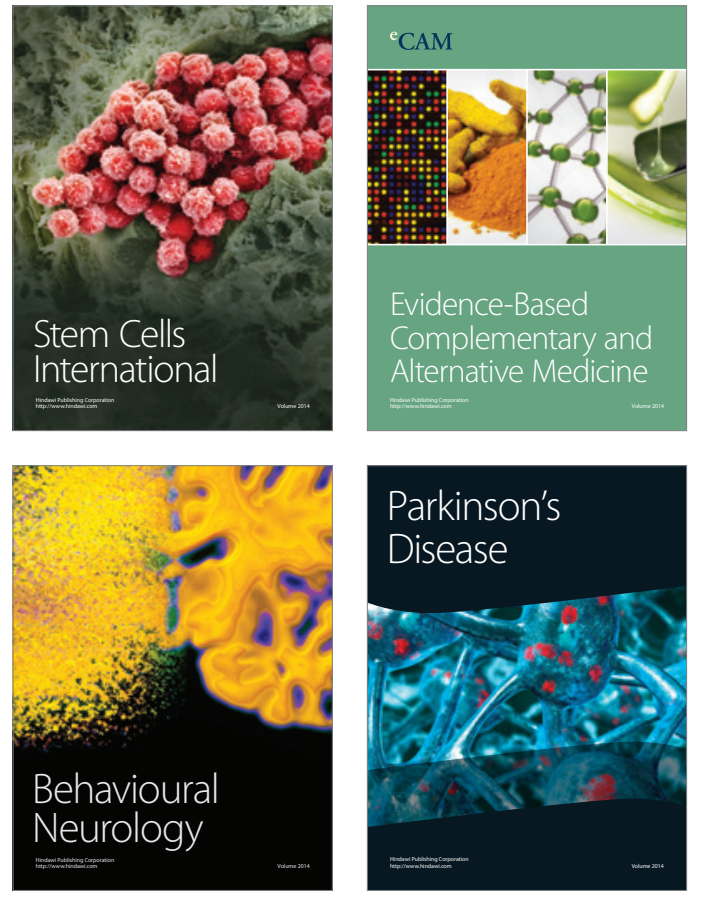
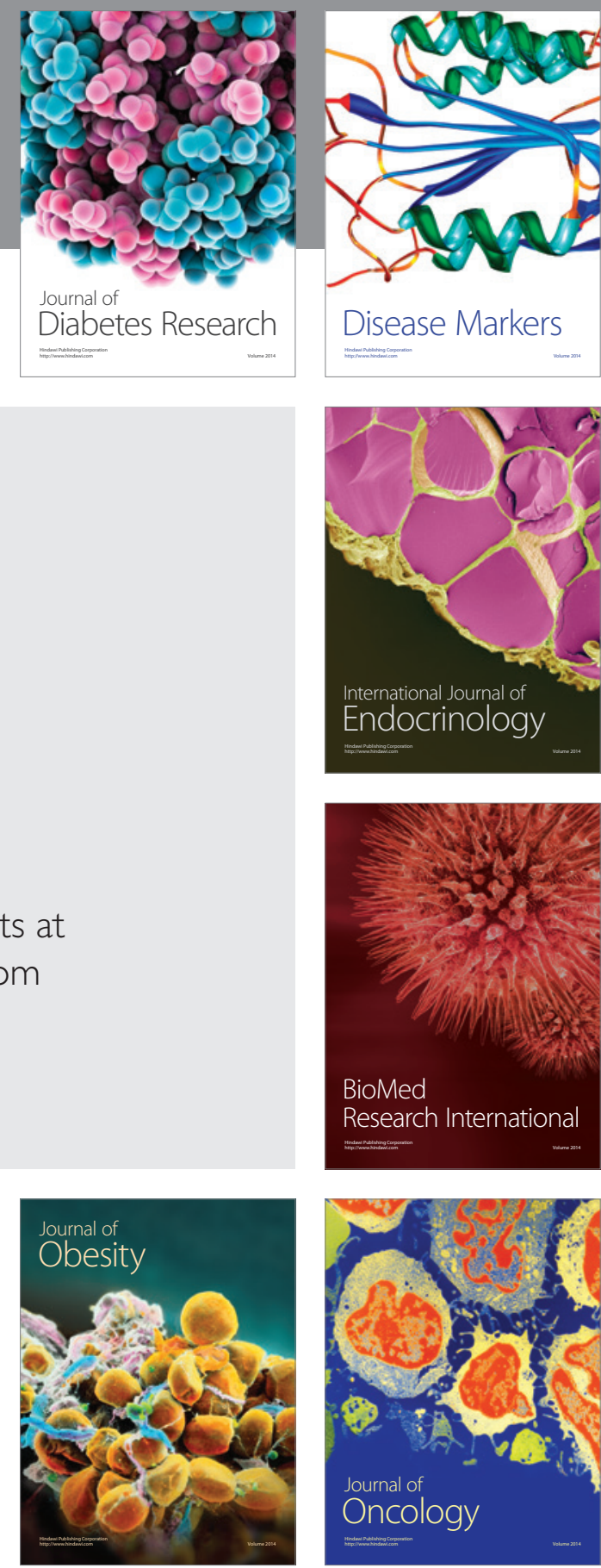

Disease Markers
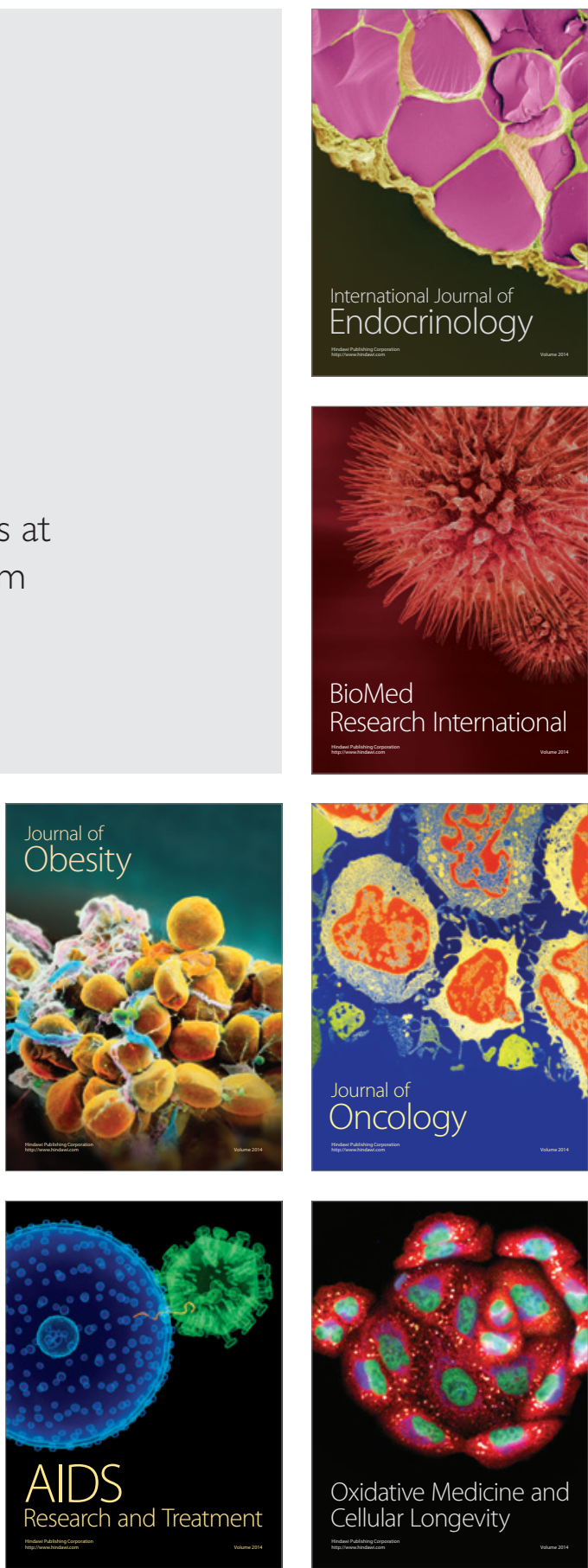